\title{
Effect of primary Phacoviscocanalostomy/ Viscocanalostomy on intraocular pressure of normal tension glaucoma patients: 3- year results
}

\author{
Derek Kwun-hong Ho, Adesuwa Garrick, Seemeen Aazem and Divya Mathews* (D)
}

\begin{abstract}
Background: The objective of this study was to evaluate the efficacy of Viscocanalostomy/Phacoviscocanalostomy (VC/PVC) in lowering intraocular pressure (IOP) in Normal Tension Glaucoma (NTG) patients.

Methods: Retrospective electronic database review of patients who underwent VC/PVC for NTG between December 2009 and November 2011 at Stanley eye unit in Abergele Hospital. Goldmann applanation tonometry (GAT) was used for all IOP measurements which were taken at the time of listing for surgery and at 1 day, 1 week, 1 month, then 3-monthly up to 1 year, then half-yearly up to 3 years post operatively. Statistical analysis was performed using unpaired t-test. A $P$ value of $<0.05$ was accepted as the level of significance.

Results: Operations were performed on 94 eyes from 67 patients over the study period. The mean age at the time of surgery was 76.4 years. Pre-operative IOP was $17.75 \pm 2.19 \mathrm{mmHg}$ (range 12-21 mmHg). 3 year follow-up showed a mean IOP of $13.41 \pm 2.22 \mathrm{mmHg}$ (range 8-18 mmHg). By year 3, 17 patients needed laser goniopuncture and 25 patients needed antiglaucoma drops. IOP was reduced by $24.4 \%$ at 3 years post-surgery, which was statistically significant $(p<0.0001)$.

Conclusions: From our results, which show a $24.5 \%$ reduction in IOP at 3 years with $12 \%$ complication rate, we propose that a logical surgical management for NTG patients would be viscocanalostomy, thereby keeping trabeculectomy as an alternative.
\end{abstract}

Keywords: Non-penetrating, Viscocanalostomy, Phacoviscocanalostomy, Normal tension glaucoma, Trabeculectomy

\section{Background}

Glaucoma is a progressive optic neuropathy which may be due, in part, to an elevated intraocular pressure (IOP) with pathognomonic changes in the optic disc and visual fields.

Normal tension glaucoma (NTG), a type of primary open angle glaucoma, can be defined with the following criteria [1].

1. A mean IOP off treatment consistently equal to or less than $21 \mathrm{mmHg}$ on diurnal testing, with no single measurement greater than $24 \mathrm{mmHg}$.

2. Open drainage angles on gonioscopy

*Correspondence: div_mat29@yahoo.co.uk

Stanley Eye Unit, Abergele Hospital, Llanfair Road, Abergele, Conwy LL22 $8 D P, U K$
3. Absence of any secondary cause for a glaucomatous optic neuropathy

4. Typical optic disc damage with glaucomatous cupping and loss of neuroretinal rim

5. Visual field defect compatible with the glaucomatous cupping (disc/field correlation)

6. Progression of glaucomatous damage.

Apart from a low/normal IOP, NTG patients are more likely to have systemic microvascular or circulatory abnormalities, such as migraine, exaggerated vasospastic response to cold recovery test, higher incidence of cerebral vascular ischemia, systemic hypertension or hypotension, or other vascular abnormalities like disc haemorrhage and peripapillary atrophy [2]. 
Following a diagnosis of NTG, (as in all forms of glaucoma) the first line of treatment is antiglaucoma drops to reduce the IOP to low teens or, in some cases, single digits. Progression, despite treatment, warrants additional antiglaucoma drops. Surgical intervention is the next option should topical treatment fail to slow progression. In the past, trabeculectomy was the only surgical option for progressive glaucoma. More recently, the concept of 'nonpenetrating' glaucoma surgery has gained interest for its potential to limit some of the complications associated with more invasive procedures to lower IOP [3]. In the mid 1990's, Stegmann et al. introduced viscocanalostomy (VC) and reported successful results in glaucoma patients from Africa [4].

The advantage of doing VC is that it can also be combined with cataract surgery (PVC) with good surgical outcomes. In comparison, phacotrabeculectomy has more complications and requires more intervention / manipulation to ensure success [5].

In VC, entry into the anterior chamber is avoided. This prevents over filtration, hypotony and as a result fewer post-operative follow up visits. However, there have been debates on the longevity as well as the efficacy of VC [6].

Few publications reported on the efficacy of VC/PVC in NTG patients. The objective of this study was to evaluate the efficacy of VC/PVC in lowering IOP in NTG patients.

\section{Methods}

Patients who underwent VC/PVC as their primary glaucoma surgery for NTG between December 2009 and November 2011, at the Stanley eye unit in Abergele Hospital, were identified from the intranet database retrospectively with no control arm. The study followed the tenets of the Declaration of Helsinki. The indication for surgery was progressive optic neuropathy, or visual fields, in patients on maximum topical antiglaucoma drops or could not tolerate antiglaucoma drops, with IOP below $21 \mathrm{mmHg}$. All procedures were performed by a single surgeon (DM) under Subtenon's anaesthesia. VC/ PVC procedures were performed by the same surgeon as previously described [4].

Post-operative follow-up for non-complicated cases was on day 1 , week 1 , month 1 and then 3 -monthly for the first year. In the immediate post-operative period, patients had topical steroids (G. prednisolone acetate $1 \%$ ) on a reducing regimen and antibiotics (G. chloramphenicol $0.5 \%$ ) for 4 weeks. IOP was measured with Goldmann Applanation Tonometry (GAT) at every visit and visual field was repeated 3 months after surgery. Laser goniopuncture (LGP) was performed if there was an increase in IOP. If an immediate drop in IOP was not achieved, antiglaucoma drops were commenced.

Statistical analysis was performed using unpaired t-test and a $P$ value of $<0.05$ was accepted as the level of significance.

\section{Results}

Ninety four eyes from 67 patients were identified, 30 of whom were male and 37 were female. The mean participant age was $76.4 \pm 9.1$ years (range $50-90$ years). Twenty five eyes had VC, of which 19 have previously undergone cataract operations, and 69 eyes had PVC. In total, 10 patients $(11 \%)$ had inadvertent perforation of the Trabeculo-Descemet's Window (TDW). The average number of topical medication prior to surgery was $2.70 \pm 0.91$, with $8.9 \pm 5.9$ years on topical antiglaucoma medication (range from 2 months to 27 years). From the database we also identified additional 4 eyes who had previous trabeculectomy and 1 had vitrectomy/cataract surgery. These were excluded from the study.

Mean pre-operative IOP was $17.75 \pm 2.19 \mathrm{mmHg}$ (range $12-21 \mathrm{mmHg}$ ). Post-operative IOP at 6 months was $12.69 \pm 2.05 \mathrm{mmHg}$ (range $8-19 \mathrm{mmHg}$ ) with one patient needing laser gonio-puncture (LGP). At 12, 24 and 36 months, mean IOP was $13.34 \pm 2.35 \mathrm{mmHg}$ (range $8-24 \mathrm{mmHg}$ ), $13.13 \pm 2.10 \mathrm{mmHg}$ (range 9$18 \mathrm{mmHg}$ ) and $13.41 \pm 2.22 \mathrm{mmHg}$ (range $8-18 \mathrm{mmHg}$ ) respectively (Fig. 1). This represents a $24.5 \%$ reduction in IOP over 3 years.

Nine patients needed LGP and 4 patients were prescribed anti-glaucoma drops by year 1 as their IOP was suboptimal. By year 2, 16 patients were prescribed anti-glaucoma drops and 11 patients received LGP treatment. By the end of study period at year 3, 17 patients had LGP and 25 patients were given antiglaucoma drops (Table 1).

There were 12 patients (13\%) lost to follow-up by 12 months. This increased to 15 (16\%) by year two and $19(20 \%)$ by the end of the three-year study period. At 12 months, percentage decrease compared to the preoperative IOP was $24.8 \%$, at 24 months the decrease was $26.0 \%$ and at 36 months $24.5 \%$. Statistical analysis using unpaired t-test showed that IOP reduction was significant $(p<0.0001)$ (Table 1$)$.

The number of anti-glaucoma drops used at 36 months was $0.28 \pm 0.58$ compared to $2.66 \pm 0.91$ pre-operatively, $0.05 \pm 0.22$ at 12 months and $0.20 \pm 0.46$ at 24 months (Fig. 2). Fifty eight operated eyes (62\%) were drop free at 36 months follow-up.

As at 36 months follow-up, 17 eyes (18\%) received LGP for sub-optimal IOP. Median time to perform LGP following VC/PVC was 12 months (range 6-36 months). Mean IOP by year 3 in this sub-group was $13.65 \pm 2.23 \mathrm{mmHg}$, reducing from the listing IOP of $18.88 \pm 1.90 \mathrm{mmHg}$, representing a reduction of $28 \% .10$ (59\%) of these 17 eyes were also commenced on antiglaucoma drops, achieving an average IOP of $13.30 \pm 2.36 \mathrm{mmHg}$ at 3 years. This compares to the 7 (41\%) out of the 17 eyes, which maintained an average IOP of $14.14 \pm 2.12 \mathrm{mmHg}$ without drops. 


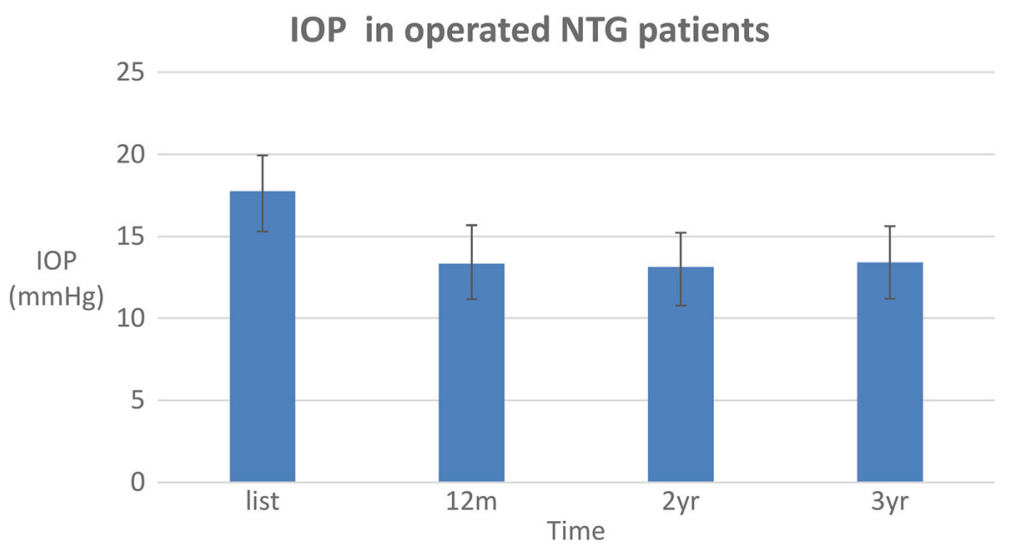

Fig. 1 Mean pre- and post-operative IOP following VC/PVC in NTG patients ( $m=$ month; yr. = years)

10 (11\%) of 94 operated eyes had inadvertent intraoperative perforation of TDW. In this group, preoperative IOP was $18.4 \pm 1.8 \mathrm{mmHg}$, reducing to $12.3 \pm 1.7 \mathrm{mmHg}$ at 6 months, $13.7 \pm 1.9 \mathrm{mmHg}$ at 12 months, $11.7 \pm 2.8 \mathrm{mmHg}$ at 24 months and $12.5 \pm 2.7 \mathrm{mmHg}$ at 36 months. Two patients needed LGP at 12 months and 4 were prescribed antiglaucoma drops by 36 months. Analysis using the unpaired t-test showed no statistical significance $(p=0.17)$ in IOP difference at 36 months, in the patients that had inadvertent perforation of the TDW and those that had an intact TDW, with 36 months IOP of $13.5 \pm 2.1 \mathrm{mmHg}$.

Comparing the pseudophakic patients who underwent $\mathrm{VC}$ and the patients who were rendered pseudophakic from their PVC surgeries, listing IOP for PVC patients was $17.70 \pm 2.33 \mathrm{mmHg}$ while VC patients IOP was $17.72 \pm 1.96 \mathrm{mmHg}(p=0.97)$. By the end of the 3 year study period, final IOP were $13.58 \pm 2.22 \mathrm{mmHg}$ and $12.92 \pm 2.36 \mathrm{mmHg}$ for PVC and VC patients respectively $(p=0.27)$. This represents a reduction of $4.1 \mathrm{mmHg}$ for PVC and $4.8 \mathrm{mmHg}$ for VC cases (Fig. 3). No significant differences in post-operative IOP between the two groups were demonstrated.

Overall, 1 patient needed conjunctiva resuturing at 1 week due to persistent leak. One patient required anterior chamber washout for hyphema 3 days post surgery and 1 other patient developed post operative cystoid macular oedema at 4 weeks. Four patients developed cystic blebs in spite of tight suturing of the flap possibly due to either thin superficial flaps or early suture dehiscence and scleral wound gape; however none of them required bleb refashioning.

At 36 months, the average Mean deviation of visual field defect was $-15.17 \pm 15.71$ (range -2.1 to -111.3 ) compared to an average of $-11.77 \pm 6.76$ (range -30.18 to -1.88 ) before surgery. Visual field analysis using unpaired t-test gave a $p$-value of 0.11 (not statistically significant).

\section{Discussion}

The collaborative normal tension Glaucoma study reported slower rate of incident visual field loss in cases of $30 \%$ or more reduction in IOP in patients with NTG [7]. This is also supported in a paper by Bhandari et al. (8).

Topical antiglaucoma drops and/laser trabeculoplasty should be used if IOP can be maintained at $30 \%$ or more below baseline $[8,9]$. In a paper published by the NTG study group titled Intraocular pressure reduction in NTG patients, $57 \%$ of the patients achieved a $30 \%$ reduction in IOP with topical medication and/with laser trabeculoplasty while the other $43 \%$ needed as single fistulising procedure [10]. In contrast, Kamal and Hitchings are of the opinion that fistulising surgery with the use of an antiproliferative agent is the treatment most likely to achieve desired IOP reduction in NTG. They also recognise the risk of post-operative hypotony [1].

One might argue that our study involves a different cohort of patients, without any control group compared to other study populations making it difficult to interpret

Table 1 Pre and post-operative IOP, with percentage reduction, at 12, 24 and 36 months

\begin{tabular}{llllll}
\hline Time & $\begin{array}{l}\text { Number of eyes } \\
\text { (loss to follow-up) }\end{array}$ & $\begin{array}{l}\text { Mean IOP }(\mathrm{SD}) \\
(\mathrm{mmHg})\end{array}$ & $\begin{array}{l}\text { Percentage IOP } \\
\text { reduction }(\%)\end{array}$ & $\begin{array}{l}\text { Number of eyes received laser } \\
\text { goniopuncture }(\mathrm{LGP})\end{array}$ & $\begin{array}{l}\text { Number of eyes receiving } \\
\text { antiglaucoma drops }\end{array}$ \\
\hline Pre-op & $94(0)$ & $17.75( \pm 2.19)$ & N/A & N/A & N/A \\
12 months & $82(12)$ & $13.34( \pm 2.35)$ & $24.8 \%$ & $9(10 \%)$ & 4 \\
24 months & $79(15)$ & $13.13( \pm 2.10)$ & $26.0 \%$ & $11(12 \%)$ & 16 \\
36 months & $75(19)$ & $13.41( \pm 2.22)$ & $24.5 \%$ & $17(18 \%)$ & 20 \\
\hline
\end{tabular}




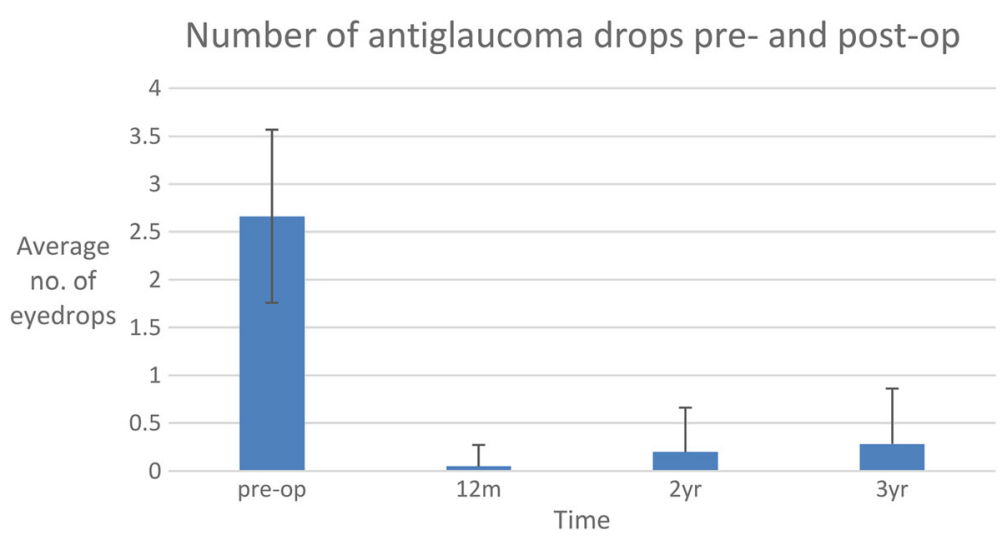

Fig. 2 Median number of anti-glaucoma medication prescribed to NTG patients pre- and post-operatively ( $\mathrm{m}=$ month; $\mathrm{yr}$. = years)

the results. Bearing this in mind our results show that IOP reduction of $24.4 \%$ at 36 months with $\mathrm{VC} / \mathrm{PVC}$ in NTG patients was comparable to that achieved with trabeculectomy. Hitchings et al. reports a reduction on IOP in NTG patients at just above $30 \%$ following trabeculectomy [11]. Similarly, Fontana et al. quotes a $25-30 \%$ reduction [12]. Membrey et al., at 2 years review, had a median reduction in IOP of $17 \mathrm{mmHg}$ following trabeculectomy with 5 flourouracil and $15.3 \mathrm{mmHg}$ following trabeculectomy with MMC [13]. The median results in our study was lower at $14 \mathrm{mmHg}$ in year 1 and 3 with $13 \mathrm{mmHg}$ in the 2 nd year.

LGP is done if IOP was increasing or if visual field progression was noticed. LGP has the potential to augment aqueous outflow through the TDW [14]. It is preferable to perform LGP rather than commencing topical medication ('rather too early than too late') [14]. 17 (18\%) of the 94 operated eyes had LGP by 3 years with a mean time to LGP from surgery of $19.9 \pm 10.8$ months. This is less than the $45 \%$ quoted for deep sclerectomy by Ambressin et al. with time to LGP from surgery of $12.4 \pm 10$ months. Our reduction in IOP post-LGP was also greater, at $28 \%$, than the $20 \%$ quoted [15]. Ten patients (59\%) were commenced on topical antiglaucoma medication as reduction in IOP following LGP was not sustained.

Fistulising procedures have documented complications. Schultz et al. reported that hypotony occurred in $30 \%$ of patients during the post-operative follow-up period [16]. Others reported complications included choroidal effusion, hyphema, hypotony maculopathy, diplopia, bleb leak, blebitis. Song et al. acknowledges the potential complications of trabeculectomy but still maintain that it is the most effective method of achieving low IOPs [3]. One should remember that trabeculectomy also warrants frequent postoperative visits at least weekly in the early post-operative period [17]. And the further use of anti-proliferative agents at least once during the post-operative visit. This translates to a lot of clinic hours spent in the frequent review of these patients in comparison to day 1,1 week, 4 weeks and 3 months post-operative visits for $\mathrm{PVC} / \mathrm{VC}$ with no intervention in the form of needling or suture adjustment. Goniopunture may be needed for PVC/VC patients but this is usually one visit any time after 6 months post operatively. The time taken to perform the laser would be similar to do doing a YAG peripheral iridotomy.

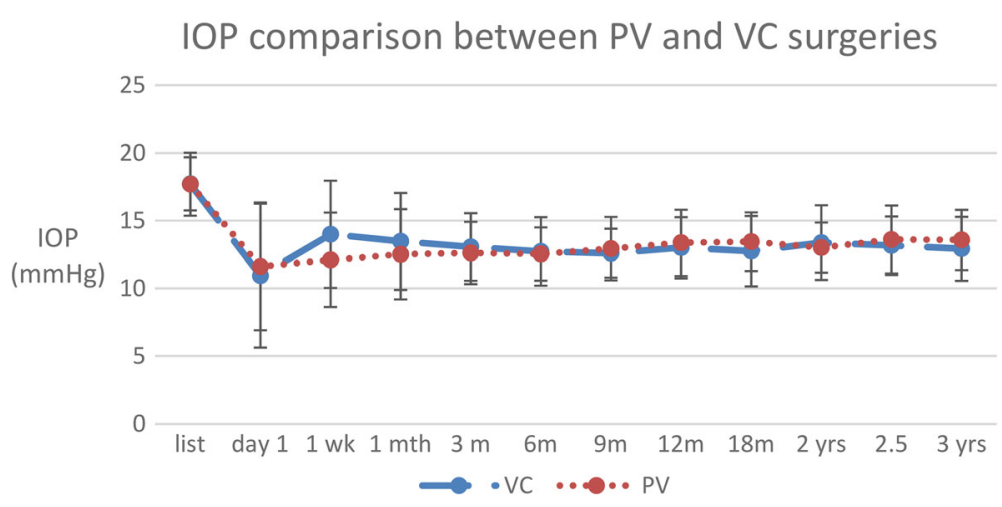

Fig. 3 Mean pre- and post-operative IOP following PVC and VC ( $m=$ month; yr. = years) 
Ophthalmic surgeons have often raised concerns on the steep learning curve for PVC/VC. However, once mastered, PVC/VC takes no longer to complete than a trabeculectomy. In our surgeon's hands, both procedures take the same time. If perforation of the TDW did occur then a surgical Peripheral Iridotomy (PI) was performed as an additional step before completing the rest of the surgical steps of $\mathrm{VC}$. This does not add any significant time to the surgery itself.

Our complication rate was low. Ten eyes (11\%) had inadvertent perforation of the TDW. Surgical PI was performed if the iris was presenting. Previous study by Park et al. documented micro-perforation rate of $21.4 \%$ and iris prolapsed from ruptured TDW in 5.9\% [18]. Similar studies on Non-penetrating glaucoma surgery (NPGS) have reported tearing of the conjunctiva, hyphema, dellen, encapsulated bleb [19]. A recent paper by Grieshaber et al. reports complications following VC including choroidal detachment, gross hyphema and peripheral Descemet's detachment [20].

We acknowledge that there are a few weaknesses in the study. Firstly it is a retrospective study. In addition the patients in our study are from a different population, without any control group compared to other studies. This might make interpretation of our results with other study populations difficult. Postoperative evaluation including Tonometry was not masked and therefore subject to observer bias. The strengths of this retrospective study includes single surgeon, long term follow-up with a large number of patients compared to similar studies.

Our study did not consider analysis of phakic versus pseudophakic eyes, as our participants included only 6 phakic eyes within the VC subgroup, compared to 88 pseudophakic eyes either from previous cataract operations or as a result of combined PVC surgeries. We considered the number of phakic eyes to be too low to draw any statistical conclusions with sufficient power.

Not analysing visual acuity is one of the weaknesses of this study. However, visual acuity is not a reliable way of judging the success of glaucoma surgery. Also, visual field analysis in previous papers was carried out using various methods, making it difficult to directly compare the results of our visual field analysis.

Membrey et al. observed that the use of MMC in trabeculectomy is associated with a greater risk on visual field progression despite a greater fall in IOP [11]. From our results, a logical surgical management for NTG patients would be viscocanalostomy keeping trabeculectomy as an alternative. We advocate viscocanalostomy for NTG patients where target IOP is in the mid-teens. In our practice, Trabeculectomy has its place in NTG patients where IOP of less than $12 \mathrm{mmHg}$ is desirable. However, we advise cardiovascular workup and ensure compliance in such patients.

\section{Conclusions}

Our study on Viscocanalostomy / Phacoviscocanalostomy operations on 94 eyes with Normal Tension Glaucoma shows $24.4 \%$ IOP reduction at 3 years. We propose viscocanalostomy as the surgical management for NTG patients, thereby keeping trabeculectomy as an alternative.

\section{Abbreviations \\ GAT: Goldmann applanation tonometry; IOP: Intraocular pressure; LGP: Laser goniopuncture; NPGS: Non-penetrating glaucoma surgery; NTG: Normal tension glaucoma; PI: Peripheral Iridotomy; PVC: Phacoviscocanalostomy; TDW: Trabeculo-Descemet's Window; VC: Viscocanalostomy}

\section{Acknowledgments \\ We would like to extend our thanks to Mr. C. S. Ng for his help and guidance on statistical analysis.}

Funding

We report no funding.

Availability of data and materials

The datasets used and/or analysed during the current study are available from the corresponding author on reasonable request.

\section{Authors' contributions}

DM conceived of and designed the study. AG, DKHH and DM collected the data. DKHH performed statistical analysis. AG, DKHH, SA and DM contributed equally to the drafting, critical revision and final approval of the manuscript.

Ethics approval and consent to participate

This study was granted ethics approval from Wales Research Ethics Committee REC 5. REC reference number: 16/WA/0345.

Consent for publication

Not applicable.

Competing interests

The authors declare that they have no competing interest.

\section{Publisher's Note}

Springer Nature remains neutral with regard to jurisdictional claims in published maps and institutional affiliations.

Received: 9 July 2017 Accepted: 1 November 2017

Published online: 06 November 2017

References

1. Kamal D, Hitchings R. Normal tension glaucoma-a practical approach. Br J Ophthalmol. 1998;82(7):835-40.

2. Daugeliene L, Yamamoto T, Kitazawa Y. Effect of trabeculectomy on visual field in progressive normal-tension glaucoma. Jpn J Ophthalmol. 1998:42(4):286-92.

3. Song BJ, Caprioli J. New directions in the treatment of normal tension glaucoma. Indian J Ophthalmol. 2014;62(5):529-37.

4. Stegmann R, Pienaar A, Miller D. Viscocanalostomy for open-angle glaucoma in black African patients. J Cataract Refract Surg. 1999;25(3): 316-22.

5. Paul C, Sengupta S, Paul A. Complications of Phacoemulsification vs Phacotrabeculectomy in the treatment of chronic angle closure glaucoma with concomitant cataract. Int J Innov Res Dev. 2013;2(9):58-66.

6. Hondur A, Onol M, Hasanreisoglu B. Nonpenetrating glaucoma surgery: meta-analysis of recent results. J Glaucoma. 2008;17(2):139-46.

7. Collaborative Normal-Tension Glaucoma Study Group. The effectiveness of intraocular pressure reduction in the treatment of normal-tension glaucoma. Am J Ophthalmol. 1998;126(4):498-505.

8. Bhandari A, Crabb DP, Poinoosawmy D, et al. Effect of surgery on visual field progression in normal-tension glaucoma. Ophthalmology. 1997; 104(7):1131-7. 
9. Geijssen HC. Studies on normal pressure glaucoma. Amsterdam: Kugler; 1991.

10. Schulzer M, The Normal Tension Glaucoma Study Group. Intraocular pressure reduction in normal-tension glaucoma patients. Ophthalmology. 1992;99(9):1468-70.

11. Hitchings RA, Wu J, Poinoosawmy $\mathrm{D}$, et al. Surgery for normal tension glaucoma. Br J Ophthalmol. 1995;79(5):402-6.

12. Fontana L, Viswanathan $A C$, Poinooswamy $D$, et al. Surgery for normal tension glaucoma. Target Intraocular Pressure and Visual Field Progression Acta Ophthalmol Scand Suppl. 1997;224:43-4.

13. Membrey WL, Bunce C, Poinoosawmy DP, et al. Glaucoma surgery with or without adjunctive antiproliferatives in normal tension glaucoma: 2 visual field progression. Br J Ophthalmol. 2001;85(6):696-701.

14. Tam DY, Barnebey HS, Ahmed II. Nd: YAG laser goniopuncture: indications and procedure. J Glaucoma. 2013:22(8):620-5.

15. Ambresin A, Shaarawy T, Mermoud A. Deep sclerectomy with collagen implant in one eye compared with trabeculectomy in the other eye of the same patient. J Glaucoma. 2002;11(3):214-20.

16. Schultz SK, Iverson SM, Shi W, et al. Safety and efficacy of achieving singledigit intraocular pressure targets with filtration surgery in eyes with progressive normal-tension glaucoma. J Glaucoma. 2016;25(2):217-22.

17. Murdoch I. Post-operative management of trabeculectomy in the first three months. Community Eye Health. 2012;25(79-80):73-5.

18. Park M, Tanito M, Nishikawa M, et al. Ultrasound biomicroscopy of intrascleral lake after viscocanalostomy and cataract surgery. J Glaucoma. 2004;13(6):472-8.

19. Suominen S, Harju M, Ihanamäki T, et al. The effect of deep sclerectomy on intraocular pressure of normal-tension glaucoma patients: 1-year results. Acta Ophthalmol. 2010;88(1):27-32.

20. Grieshaber MC, Peckar C, Pienaar A, et al. Long-term results of up to 12 years of over 700 cases of viscocanalostomy for open-angle glaucoma. Acta Ophthalmol. 2015;93(4):362-7.

\section{Submit your next manuscript to BioMed Central and we will help you at every step:}

- We accept pre-submission inquiries

- Our selector tool helps you to find the most relevant journal

- We provide round the clock customer support

- Convenient online submission

- Thorough peer review

- Inclusion in PubMed and all major indexing services

- Maximum visibility for your research

Submit your manuscript at www.biomedcentral.com/submit

) Biomed Central 